\title{
The Empirical Research on the Impact of Digital Currency on Monetary Liquidity and Currency Multiplier \\ SHAO Fenghua
}

School of computer science and information Engineering, Hubei University, Wuhan, Hubei, China,430062

441550842@qq.com

36636406@qq.com

Key words: digital currency; recursive neural network; unscented Kalman filter algorithm; the velocity of currency circulation;money multiplier

\begin{abstract}
First, this paper establishes an AI model to simulate the issuance of currency. Based on VAR model, recursive neural network and state space model, the model simulates the issuance of digital currency under certain conditions, and uses the lossless Kalman filter algorithm for deep learning and weight correction. Second, on the basis of money supply theory, this paper analyzes the impact of digital currency on currency circulation speed and money multiplier through empirical research , such as the unit root test of time series,co-integration test, error correction model of different variables in the short term. There is a definite possibility that the network effect of digital currency accelerates the velocity of money circulation in different periods. The more trading entities, the greater the growth. In addition, the digital currency also has an impact on the currency multiplier, which increases the leverage ratio and risk accumulation of the financial system and the difficulty of financial supervision. Finally, this paper puts forward that the digital currency trading system can be regulated by designing a controllable anonymity algorithm for digital currency.
\end{abstract}

\section{Simulations of Currency}

Both observable factors(such as inflation rate,actual output,etc.) and indirect observable factors(such as natural interest rate and potential output,etc.) could play a part in issuing currency.

The VAR model is designed for observable economic variables. The general form is:

$$
u_{t}=\Phi_{1} u_{t-1}+\Phi_{2} u_{t-2}+\cdots+\Phi_{p} u_{t-p}+\varepsilon_{t} \varepsilon_{t} \sim \text { i.i.d. } N(0, \Omega)
$$

In order to describe economic variables that are not directly observable, state space models are often used for estimation. The state space model uses state equations to describe the evolution of state variables of unknown systems at different time, and uses the measurement equation to describe the intrinsic relationship between observable variables and state variables. This method is called recursive neural network based on state space equation. The study process of the neural network is a process of constantly adjusting the "connection rights" between neurons and the threshold of each functional neuron according to the training data.Besides, the weight of the network can be renewed by recursive neural network according to the unscented Kalman filter algorithm (UKF).

$$
\begin{gathered}
y_{t}=f\left(x_{t}, u_{t}, \varepsilon_{1 t}\right)=W_{a} x_{t}+\varepsilon_{1 t} \\
x_{t+1}=h\left(x_{t-1}, u_{t}, \varepsilon_{2 t}\right)=\varphi\left(W_{b} x_{t}+W_{c} u_{t}\right)+\varepsilon_{2 t}
\end{gathered}
$$

Wa refers to the weighted connection between the hidden layer neurons and the output layer neurons. Wb refers to the weighted connection between the hidden layer neurons and the feedback node in the input layer.Wc refers to the weighted connection between input layer neurons and hidden layer neurons. The nonlinear function $\varphi$ refers to the sigmoid activation function of the hidden layer neurons. The output vector $y_{t}$ presents the currency issuance at time t.The input vector $u_{t}$ presents the observable variables at time t.The state vector $x_{t}$ presents the unknown state variables at time $\mathrm{t}$. 


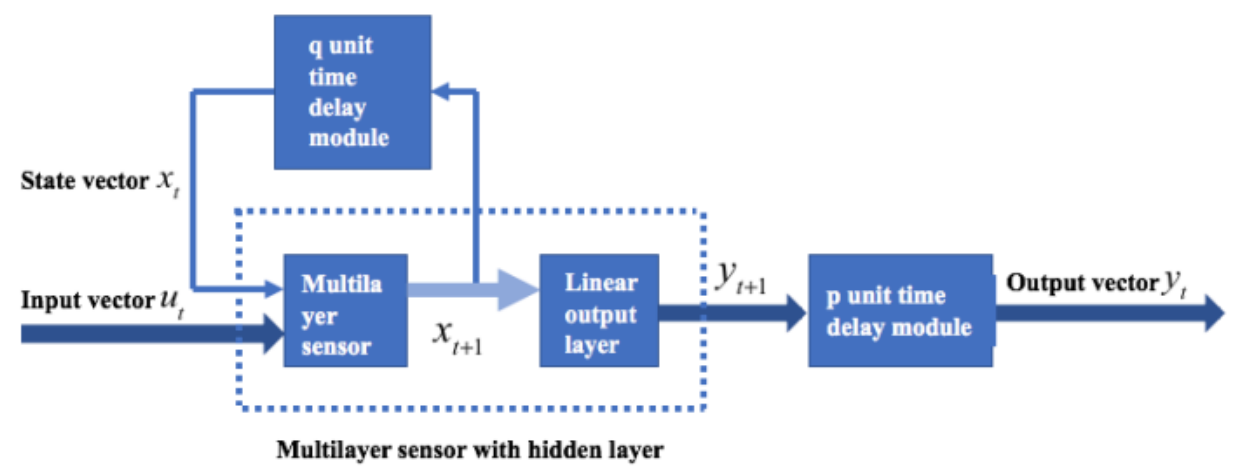

Figure 1: recursive neural network based on state space equation.

Provided that the issued digital currency features permanent validity,free settlement and maximum circulation, the incremental circulation can be modified by the difficulty of the mining algorithm.

By setting relevant variables ,such as one-year deposit race,M0,M1,M2 in recent years,etc.,currency issuance in 2018-2023 can be evaluated.

\section{2.the Impact of Digital Currency on Monetary Liquidity}

Suppose V1 represents the narrow money circulation speed and V2 represents the general circulation speed.The fluctuation of velocity can be calculated in accordance with Fisher equation. $\mathrm{MV}=\mathrm{PY}, \mathrm{V}=\mathrm{PY} / \mathrm{M}=\mathrm{GDP} / \mathrm{M} \circ \mathrm{V}_{1}=\mathrm{GDP} / \mathrm{M} 1, \mathrm{~V}_{2}=\mathrm{GDP} / \mathrm{M} 2$. To figure out the correlation and dependence between currency circulation and velocity, the research selects your indicators,DI,RR,OBTF and FMD.The stability of sequence is analyzed by DF unit root test. After verifying single integral sequence under same order,the co-integration between velocity and indicators becomes clear.Then,the conclusion comes into being based on co-integration and error correction model.

(1) Indicator selection

1. Resident disposable income (DI)

The volatility of the data can be reduced by taking the logarithm.

2. Real interest rate (RR)

When the real interest rate rises, people tend to increase deposits, leading to lower cash holdings, quicker cash flow, an increase of v1 and a decrease of v2. This article uses the one-year deposit rate minus the inflation rate to represent the actual interest rate,reflecting the opportunity for people to hold money.

3. Digital Currency Trading Frequency (OBTF)

This index is a ratio that takes into account total payment currency and M2,indicating the frequency with which the society uses digital currency payments. The more developed the digital currency payment, the greater the value of this indicator. It reflects the substitution of digital currency payment for traditional one in circulation to some extent.

\section{Financial Modernization (FMD)}

Defined as FMD $=(\mathrm{M} 2-\mathrm{M} 0) / \mathrm{M} 2$, the value is directly affected by the proportion of non-cash currencies in the country. Technology development and financial innovation accelerate the transition of the monetary level from a low-level M0 to a more advanced M1, M2.

(2)Unit root test

This paper applies DF unit Root test to judge the stability of the sequence by Eviews. The result shows that the original sequences V1,V2,OBTF,FMD,LNDI,RR are not stable.The first-order difference is followed by the DF unit root test, which shows that the first-order difference sequence is stable under $1 \%$ confidence. Unit root test shows that the first order difference sequence is the same order single sequence. 
TABLE 1: Unit Root Test of Variables.

\begin{tabular}{|c|c|c|c|c|c|c|c|c|c|c|c|c|c|}
\hline & & \multicolumn{2}{|c|}{$\mathrm{V}_{1}$} & \multicolumn{2}{|c|}{$\mathrm{V}_{2}$} & \multicolumn{2}{|c|}{ OBTF } & \multicolumn{2}{|c|}{ FMD } & \multicolumn{2}{|c|}{$\ln D I$} & \multicolumn{2}{|c|}{$\mathrm{RR}$} \\
\hline & & $\begin{array}{r}\text { Original } \\
\text { sequence }\end{array}$ & $\begin{array}{c}\text { First-o } \\
\text { rder } \\
\text { derivat } \\
\text { ive } \\
\end{array}$ & $\begin{array}{r}\text { Original } \\
\text { sequence }\end{array}$ & $\begin{array}{c}\text { First-order } \\
\text { derivative }\end{array}$ & $\begin{array}{c}\text { Origina } \\
1 \\
\text { sequen } \\
\text { ce } \\
\end{array}$ & $\begin{array}{c}\text { First-or } \\
\text { der } \\
\text { derivati } \\
\text { ve } \\
\end{array}$ & $\begin{array}{c}\text { Original } \\
\text { sequence }\end{array}$ & $\begin{array}{c}\text { First-or } \\
\text { der } \\
\text { derivati } \\
\text { ve } \\
\end{array}$ & $\begin{array}{l}\text { Original } \\
\text { sequenc } \\
\mathrm{e}\end{array}$ & $\begin{array}{c}\text { First-ord } \\
\text { er } \\
\text { derivativ } \\
\mathrm{e}\end{array}$ & $\begin{array}{c}\text { Origina } \\
1 \\
\text { sequen } \\
\text { ce } \\
\end{array}$ & $\begin{array}{c}\text { First-or } \\
\text { der } \\
\text { derivati } \\
\text { ve } \\
\end{array}$ \\
\hline \multicolumn{2}{|c|}{ result } & -2.33 & -9.90 & -1.99 & -10.66 & -0.29 & -0.62 & -1.20 & -8.07 & -1.06 & -13.23 & -2.41 & -5.98 \\
\hline \multirow{3}{*}{ threshold } & $1 \%$ & -3.57 & -3.57 & -3.57 & -3.57 & -3.57 & -3.57 & -3.57 & -3.57 & -3.57 & -3.57 & -3.57 & -3.57 \\
\hline & $5 \%$ & -2.92 & -2.92 & -2.92 & -2.92 & -2.92 & -2.92 & -2.92 & -2.92 & -2.92 & -2.92 & -2.92 & -2.92 \\
\hline & $10 \%$ & -2.60 & -2.60 & -2.60 & -2.60 & -2.60 & -2.60 & -2.60 & -2.60 & -2.60 & -2.60 & -2.60 & -2.60 \\
\hline \multicolumn{2}{|c|}{ conclusion } & \multicolumn{2}{|c|}{$\begin{array}{l}\text { First-order stable } \\
\text { progress }\end{array}$} & \multicolumn{2}{|c|}{$\begin{array}{l}\text { First-order stable } \\
\text { progress }\end{array}$} & \multicolumn{2}{|c|}{$\begin{array}{l}\text { First-order stable } \\
\text { progress }\end{array}$} & \multicolumn{2}{|c|}{$\begin{array}{l}\text { First-order stable } \\
\text { progress }\end{array}$} & \multicolumn{2}{|c|}{$\begin{array}{l}\text { First-order stable } \\
\text { progress }\end{array}$} & \multicolumn{2}{|c|}{$\begin{array}{l}\text { First-order stable } \\
\text { progress }\end{array}$} \\
\hline
\end{tabular}

(***means being stable under $1 \%$ confidence; ${ }^{* *}$ means being stable under $5 \%$ confidence; ${ }^{*}$ means being stable under $10 \%$ confidence)

(3)Co-integration test

Co-integration may exist only when the variables are all same-order integer variables. In the unit root test, it has been proved that V1, V2, OBTF, FMD, LNDI, and RR are the same-order single-integer sequence. Check if there is a co-integration in the sequence.

The first step is to perform co-integration regression. The equation is estimated by the OLS method and the unbalanced error $\widehat{e_{t}}$ is calculated.

$$
\begin{array}{cc}
V_{1}=0.183 L N D I+0.293 R R+0.072 O B T F & 5.783 F M D+5.968 \\
V_{2}=0.0863 L N D I+0.0721 R R+0.0187 O B T F & 2.408 F M D+2.7539
\end{array}
$$

In the second step, the integrity of the non-equilibrium error is tested by the DF test. The results are as follows:

\begin{tabular}{|c|c|c|c|c|c|}
\hline variables & $\mathrm{t}$ & \multicolumn{3}{|c|}{ threshold } & conclusion \\
\hline & & $1 \%$ & $5 \%$ & $10 \%$ & \\
\hline $\mathrm{R} 1$ & -4.816 & -3.569 & -2.924 & -2.597 & stable \\
\hline $\mathrm{R} 2$ & -7.096 & -3.569 & -2.924 & -2.597 & stable \\
\hline
\end{tabular}

TABLE 2: unit root test for $\widehat{e_{t}}$.

According to the test results from Eviews, at the 1\% confidence level, the non-equilibrium error sequence is a stable sequence, so the variables V1, V2, OBTF, FMD, LNDI, RR have a co-integration relationship.

(4) Error correction model

According to the Grange theorem, if the time series is co-integrated, the short-term non-equilibrium relationship can be expressed by an error correction model, and the value of the dependent variable is corrected by the long-term non-equilibrium error term. Using the Johansen test to determine the lag order is 2 , after eliminating the insignificant variables, the error correction model is as follows: $\Delta V_{1 t}=-0.174 e^{e} m_{t-1}(-1)$ $+0.322 e^{2} m_{t-2}+0.280 \Delta L N D I_{1, T-2}+0.056 \Delta O B T F_{1, t-2}-1.182 \Delta F M D_{t-1}$

The coefficient of the lag phased error correction term is -0.174 , indicating that the non-equilibrium state will adjust to the equilibrium state by 0.174 ,due to the short-term fluctuation deviating from the long-term equilibrium. In the short term, the change in the traditional currency circulation speed V1 can be divided into two parts: a rise of 1 unit $\Delta L N D I_{1}, t-2$ will cause an increase of 0.28 unit $\Delta V_{1 t}$, a change of 1 unit $\triangle O B T F_{1, t-2}$ will cause an increase of 0.056 unit $\Delta V_{1 t}$.

$$
\begin{gathered}
\Delta V_{2 t}=-0.245 e \mathrm{~cm}_{t-1}(-1)+0.083 \mathrm{ecm}_{t-2}(-2)-0.424 \Delta V_{2, t-1}-0.532 \Delta V_{2, t-2} \\
-0.712 \Delta V_{2, t-3}+0.048 \Delta L N D I_{2, t-2}+0.153 \Delta O B T F_{2, t-2} \\
+0.0124 \Delta O B T F_{2, t-3}-0.1653 \Delta F M D_{1, t-2}
\end{gathered}
$$

In the short term, changes in V2 can be explained by four parts. 
(1) $\Delta V_{2, t-1}, \Delta V_{2, t-2}, \Delta V_{2, t-3}$ has a negative influence on $\Delta V_{2 t}$.

(2) a rise of 1 unit $\triangle L N D I_{2}, t-2$ will cause an increase of 0.048 unit $\Delta V_{2 t}$.

(3) a rise of 1 unit $\triangle O B T F_{2, t-2}, \triangle O B T F_{2, t-3}$ will cause an increase of 0.0153 unit, 0.0124 unit $\Delta V_{2 t}$ respectively.

(4) a change of 1 unit $\Delta F M D_{2, t-2}$ will cause a decrease of $\Delta V_{2 t}$.

(4)Analysis of results

The empirical research shows that in the long-term equilibrium, the development of digital currency payment accelerates the circulation of money, and influences it in the short term. In addition, the higher financial modernization, the greater the value of FMD $=(\mathrm{M} 2-\mathrm{M} 0) / \mathrm{M} 2$, the slower the currency circulation.

The development of digital currency has an alternative acceleration effect and an alternative conversion effect on traditional currencies. These two effects have different effects on the velocity of money circulation and monetary level. The alternative acceleration effect refers to the advantage that digital currency speed up the circulation of money compared to traditional currency; the substitution conversion effect accelerates the transition between different monetary levels. On the one hand, digital currency payments have got rid of time and space restrictions, the substitution speeds up the flow of money. On the other hand, the existence of digital currency obscures the traditional monetary level, leading to a quicker and easier conversion between different levels. Besides, the digital currency payment costs down the opportunity holding high-yield financial assets (such as stocks, bonds, etc.). Therefore, the higher proportion of digital currency lowers V1, V2.

\section{3.the impact of digital currency on the currency multiplier}

(1) Indicator selection

1. Cash leakage rate (CLR)

The cash leakage rate is the ratio of cash leakage to total bank deposits. It is a measure of the cash outflow banking system. This part of the cash is directly distributed outside the banking system and without deposit creation. The cash leakage rate is usually measured by M0/M2. It is an important factor affecting the money multiplier. On the one hand, its changes influence the ratio of excessive reserve in commercial banks. When the cash leakage rate increases, Commercial banks must retain more excessive reserve in order to meet the needs of customers to withdraw cash, thus declining the funds for loans and investments. On the other hand, excessive cash leakage will reduce the original deposits of commercial banks, resulting in a decrease of currency creation capacity in bank. Both of these effects result in a negative correlation between the cash leakage rate and the currency multiplier.

2. Digital Currency Trading Frequency (OBTF)

3. Narrow money multiplier (MM1), broad money multiplier (MM2)

(2) VAR model

The VAR model calculates relevant variables and determines the lag period, reflecting the vast majority of the interaction between the variables. According to the unit root test, all sequences are first-order and single-order integer, so the VAR model is established with $\Delta \mathrm{MM}, \Delta \mathrm{OBTF}$, and $\triangle$ CLR. On the basis of AIC and SC criteria, the optimal lag order of the variable is 4 , and the regression result is as follows: 


$$
\begin{aligned}
& \left(\begin{array}{c}
\Delta M M 1_{t} \\
\Delta O B T F_{t} \\
\Delta C L R_{t}
\end{array}\right)=\left(\begin{array}{c}
0.0044 \\
0.5856 \\
-0.0015
\end{array}\right)+\left(\begin{array}{ccc}
0.0432 & -0.1894 & -0.0450 \\
-1.8944 & -0.1348 & -10.7755 \\
-0.0450 & -0.0019 & -0.3698
\end{array}\right)\left(\begin{array}{c}
\Delta M M 1_{t-1} \\
\Delta O B T F_{t-1} \\
\Delta C L R_{t-1}
\end{array}\right) \\
& +\left(\begin{array}{ccc}
0.4603 & 3.1884 & -0.0390 \\
3.1884 & 0.1598 & 17.0342 \\
-0.0390 & -0.0030 & -0.3140
\end{array}\right)\left(\begin{array}{c}
\Delta M M 1_{t-2} \\
\Delta O B T F_{t-2} \\
\Delta C L R_{t-2}
\end{array}\right) \\
& +\left(\begin{array}{ccc}
0.0493 & -0.0260 & 1.6284 \\
4.2448 & -0.2886 & 34.6149 \\
-0.0030 & -0.0025 & -0.2322
\end{array}\right)\left(\begin{array}{c}
\Delta M M 1_{t-3} \\
\Delta O B T F_{t-3} \\
\Delta C L R_{t-3}
\end{array}\right) \\
& +\left(\begin{array}{ccc}
-0.1235 & -0.0086 & -3.0848 \\
-1.9327 & -0.1896 & 1.1314 \\
-0.0024 & -0.0032 & 0.6547
\end{array}\right)\left(\begin{array}{c}
\Delta M M 1_{t-4} \\
\Delta O B T F_{t-4} \\
\Delta C L R_{t-4}
\end{array}\right)+\left(\begin{array}{l}
\varepsilon_{1 t} \\
\varepsilon_{2 t} \\
\varepsilon_{3 t}
\end{array}\right) \\
& \begin{aligned}
\left(\begin{array}{c}
\Delta M M 2_{t} \\
\Delta O B T F_{t} \\
\Delta C L R_{t}
\end{array}\right)= & \left(\begin{array}{l}
0.0529 \\
0.4254 \\
0.0001
\end{array}\right)+\left(\begin{array}{ccc}
0.0356 & -0.0307 & -0.0428 \\
-0.2856 & -0.1412 & -5.1931 \\
-0.0186 & -0.0016 & -0.3438
\end{array}\right)\left(\begin{array}{c}
\Delta M M 2_{t-1} \\
\Delta O B T F_{t-1} \\
\Delta C L R_{t-1}
\end{array}\right) \\
& +\left(\begin{array}{ccc}
0.6681 & 12.7362 & -0.6128 \\
4.2891 & -0.3778 & 23.2182 \\
-0.1242 & -0.1927 & -0.9215
\end{array}\right)\left(\begin{array}{c}
\Delta M M 1_{t-2} \\
\Delta O B T F_{t-2} \\
\Delta C L R_{t-2}
\end{array}\right) \\
& +\left(\begin{array}{ccc}
0.1726 & -0.0635 & 1.9217 \\
5.2781 & -0.7812 & 26.1278 \\
-0.0912 & -0.0184 & 1.3871
\end{array}\right)\left(\begin{array}{c}
\Delta M M 2_{t-3} \\
\Delta O B T F_{t-3} \\
\Delta C L R_{t-3}
\end{array}\right) \\
& +\left(\begin{array}{ccc}
-0.7781 & -0.0671 & -4.1721 \\
-2.2013 & -0.0931 & 7.2112 \\
-0.3626 & -0.0126 & 0.8799
\end{array}\right)\left(\begin{array}{c}
\Delta M M 2_{t-4} \\
\Delta O B T F_{t-4} \\
\Delta C L R_{t-4}
\end{array}\right)+\left(\begin{array}{c}
\varepsilon_{1 t} \\
\varepsilon_{2 t} \\
\varepsilon_{3 t}
\end{array}\right)
\end{aligned}
\end{aligned}
$$

(3) Variance decomposition

The main purpose of variance decomposition is to analyze the influence factors of the impact of each variable on the changes of endogenous variables, and then use the data to divide the impact strength and impact degree of the relevant variables. Variance decomposition requires the establishment of a decomposition model of the prediction variance and identifies the contribution of the prediction variance. Variance decomposition can be regarded as the importance of dynamic changes in MM1, MM2, OBTF and CLR. The variance decomposition is performed according to the above analysis and model. The following table is the result of the decomposition of the contribution to the relevant variables by Eview:

TABLE 3: Contribution of digital currency payment frequency to narrow money multiplier

\begin{tabular}{|c|c|c|c|c|c|c|c|c|c|}
\hline \multirow{3}{*}{ Period } & \multicolumn{3}{|c|}{ Variance decomposition on } & \multicolumn{2}{c|}{ Variance decomposition on OBTF } & \multicolumn{3}{c|}{ Variance decomposition on } \\
& \multicolumn{3}{|c}{ CM1 (\%) } & \multicolumn{3}{c|}{ (\%) } \\
\cline { 2 - 10 } & $\Delta$ DMM1 & $\Delta$ OBTF & $\Delta$ CLR & $\Delta$ DMM1 & $\Delta$ OBTF & $\Delta$ CLR & $\Delta$ DMM1 & $\Delta$ OBTF & $\Delta$ CLR \\
\hline 1 & 1.0000 & 0.0000 & 0.0000 & 0.0187 & 0.9836 & 0.0000 & 0.2695 & 0.0342 & 0.6982 \\
\hline 2 & 0.9418 & 0.0367 & 0.0229 & 0.0265 & 0.9552 & 0.0183 & 0.2492 & 0.0343 & 0.7918 \\
\hline 3 & 0.7703 & 0.0457 & 0.1875 & 0.0323 & 0.8654 & 0.0974 & 0.2458 & 0.0526 & 0.7022 \\
\hline 4 & 0.7268 & 0.1062 & 0.1748 & 0.0329 & 08302 & 0.1316 & 0.2427 & 0.0598 & 0.7064 \\
\hline 5 & 0.6843 & 0.1056 & 0.2185 & 0.0521 & 0.8022 & 0.1368 & 0.2519 & 0.0409 & 0.6894 \\
\hline 6 & 0.6797 & 0.1093 & 0.2195 & 0.0531 & 0.8030 & 0.1392 & 0.2513 & 0.0704 & 0.6795 \\
\hline 7 & 0.6806 & 0.1098 & 0.2143 & 0.0696 & 0.7910 & 0.1482 & 0.2564 & 0.0698 & 0.6811 \\
\hline 8 & 0.6726 & 0.1154 & 0.2113 & 0.0603 & 0.7893 & 0.1458 & 0.2609 & 0.0693 & 0.6692 \\
\hline
\end{tabular}

From the table, it can be seen that in the first period, the money multiplier is only affected by its own fluctuations. The impact of digital currency and cash leakage on the narrow money multiplier volatility was weaker in the second phase, only about $6 \%$, and then gradually increased, and stabilized at around $32 \%$ from the fifth period. This suggests that the growth of the money 
multiplier is affected by the cash leakage rate and the frequency of digital currency payments. There are many uncertain factors that affect the money multiplier. In the current period, the frequency of digital currency payments has limited impact. From the first period, the frequency of digital currency payment is affected by its own fluctuations and currency multipliers, and its own fluctuations have a greater impact, but gradually weaken.

TABLE 4: Contribution of digital currency payment frequency to narrow money multiplier

\begin{tabular}{|c|c|c|c|c|c|c|c|c|c|}
\hline \multirow{3}{*}{ Period } & \multicolumn{3}{|c|}{ Variance decomposition on } & \multicolumn{3}{c|}{ Variance decomposition on } & \multicolumn{3}{c|}{ Variance decomposition on } \\
& \multicolumn{3}{|c}{ MM2 (\%) $(\%)$} & \multicolumn{2}{c|}{ OBTF(\%) } \\
\cline { 2 - 10 } & $\Delta$ DMM2 & $\Delta$ OBTF & $\Delta$ CLR & $\Delta$ DMM2 & $\Delta$ OBTF & $\Delta$ CLR & $\Delta$ DMM2 & $\Delta$ OBTF & $\Delta$ CLR \\
\hline 1 & 1.0000 & 0.0000 & 0.0000 & 0.0198 & 0.9836 & 0.0000 & 0.1219 & 0.0500 & 0.8283 \\
\hline 2 & 0.9817 & 0.0167 & 0.0000 & 0.0174 & 0.9752 & 0.0045 & 0.1420 & 0.0453 & 0.8129 \\
\hline 3 & 0.6368 & 0.0836 & 0.2775 & 0.0168 & 0.9056 & 0.0725 & 0.1327 & 0.0729 & 0.7854 \\
\hline 4 & 0.6339 & 0.0958 & 0.2726 & 0.0162 & 08962 & 0.0832 & 0.1689 & 0.0709 & 0.7923 \\
\hline 5 & 0.6095 & 0.1007 & 0.2902 & 0.0514 & 0.8523 & 0.0826 & 0.1476 & 0.0628 & 0.7943 \\
\hline 6 & 0.6008 & 0.1000 & 0.2980 & 0.0542 & 0.8540 & 0.0954 & 0.1325 & 0.0896 & 0.7826 \\
\hline 7 & 0.5672 & 0.0937 & 0.3457 & 0.0569 & 0.8509 & 0.0962 & 0.1437 & 0.0871 & 0.7708 \\
\hline 8 & 0.5628 & 0.1045 & 0.3446 & 0.0536 & 0.8493 & 0.1003 & 0.1416 & 0.0838 & 0.7625 \\
\hline
\end{tabular}

The variance decomposition table is obtained by analyzing the variance of the broad money multiplier, the digital currency payment frequency and the cash leakage rate. As can be seen from the table, the money multiplier is only affected by its own fluctuations in the first stage. The effect of digital currency payment frequency and cash leakage loss on the broad money multiplier gradually clears in the later period. With time went on, the influence of these two variables gradually increased, eventually stabilizing at around $44 \%$. The first period of the digital currency payment frequency is affected by its own fluctuations and currency multipliers, mainly by its own influence. After the first period, its own influence gradually weakened, but continued. Finally, when analyse the cash leakage rate, in the first stage, the cash loss rate is affected by its own, currency leakage rate and currency multiplier. The main factor is its own lagging variable and this factor will be weakened over time. In the end, the impact of MM2 and OBFT on CLR gradually stabilized at around $22 \%$.

(4)Analysis of results

The empirical results show that OBTF is positively correlated with MM1 and MM2. An increase in the Digital Currency Payment Frequency (OBTF) will amplify the currency multiplier. This should consider two factors: on the one hand, the development of online payment promotes the development of Internet finance and virtual economy, reduces the cash leakage rate, and has an advantage over traditional payment. Online payments do not require intermediation between bank, reducing the usage rate of traditional currencies, thus decreasing the cash leakage rate. The cash leakage rate (CLR) is negatively correlated with MM. If the CLR rises, MM decreases. Therefore, the increase in the frequency of online payment of digital currency increases the currency multiplier. On the other hand, the development of online payments has accelerated the growth of digital currencies. When the scale of the digital currency is large enough to reduce the deposit reserve ratio, the money multiplier increases.

\section{Regulatory Advice}

(1) Design of controllable anonymity algorithm for digital currency

This paper proposes a verification method using a double-chain supervision model. The system consists of three main modules: user wallets, consortium blockchains (including supervision) and public blockchains. The communication between nodes in the system adopts $\mathrm{P} 2 \mathrm{P}$ mode. There is no difference between the server and the client except for the tasks performed by the node. The user wallet is the initiator of transactions in the system, managing public keys, private keys, and transactions with legal money for easier access and use. The consortium blockchains shoulders the receipt and verification, and records in the box. The public blockchains transaction is a certificate for the verification and user wallet accounts. 
The flow chart for monitoring transactions in the digital currency system is as follows:

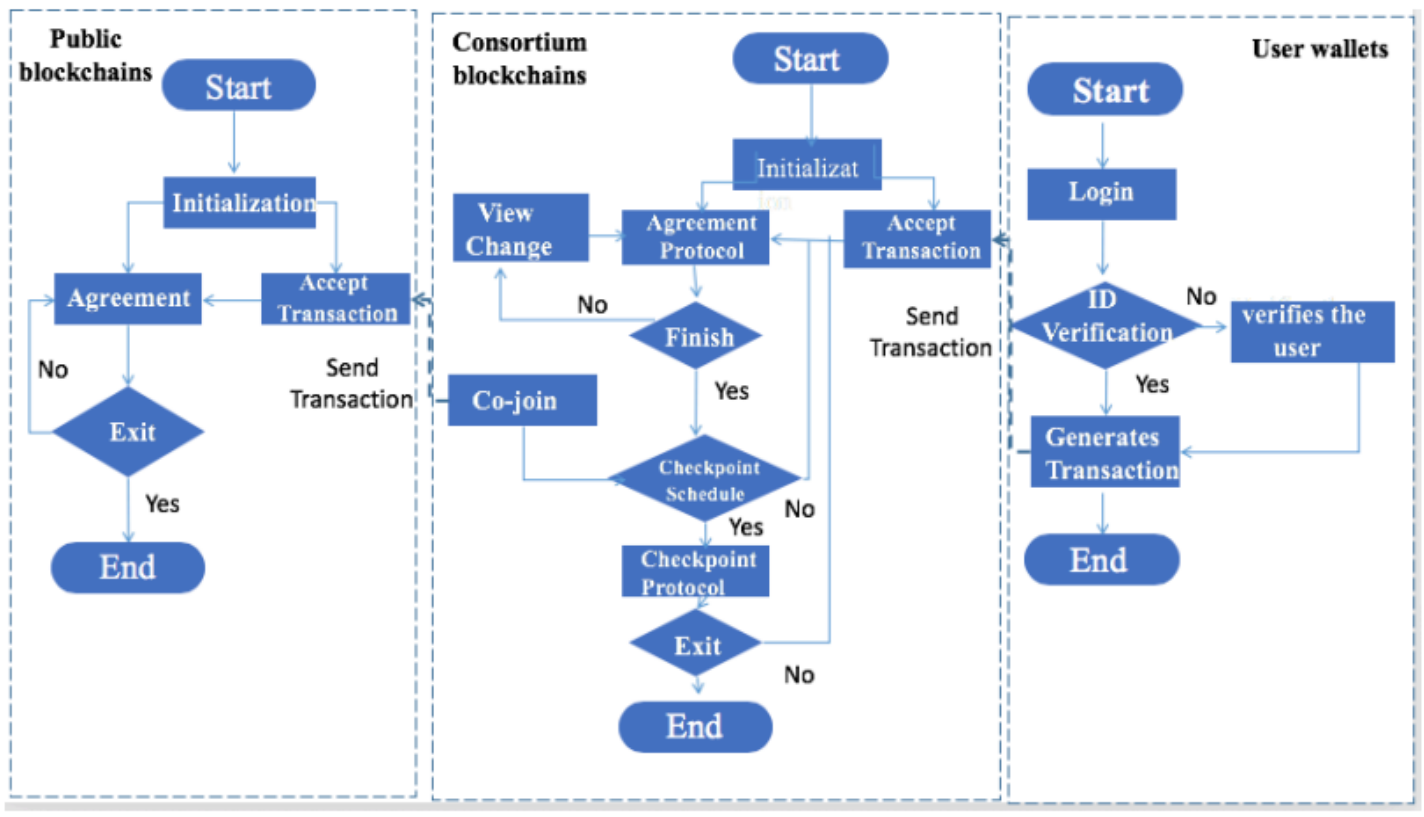

Figure 2: Supervised process of the digital currency trading system

In this system, the public blockchains and the consortium blockchains are equivalent, but different in handling information. These two parts can be combined as a server, while the user is the client that sends an operation request to the server.

The following figure illustrates the tracking process that only occurs between consortium blockchains nodes. The head node sends requests to other consortium blockchains, including supervisory nodes. The consortium blockchains chain in the following figure includes more than one node. After the supervisory node recovers the key, it sends a request to verify the user information.

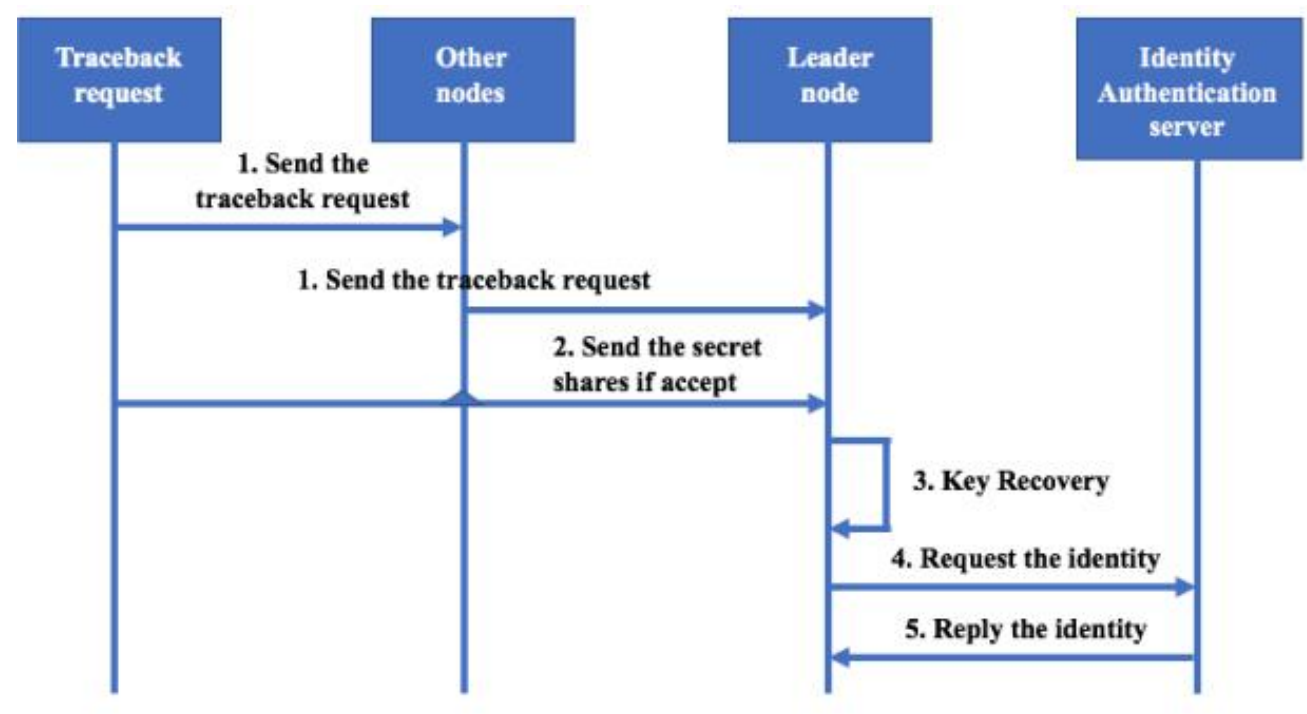

Figure 3: Tracking process

(2) Analysis of the necessity of supervision

Currency circulation should be controlled, for the reason that anti-inflation advantage will be greatly reduced if the digital currency be arbitrarily quantified. Therefore, it is recommended to use technology and protocols to control the flow of digital currency. In the terms of technology, algorithms can limit digital currency circulation to a set-point. In the terms if protocol, arbitrary distribution of digital currencies can be eliminated by agreement. 


\section{Conclusions and recommendations}

1.There are three stages in the development of digital currency: currency substitution, fixed rate conversion with legal money, and legal currency. Currency substitution refers to the non-official holding of digital currency. The digital currency is official but informal at the stage of a fixed rate exchange with the legal money. Different from the first two stages, when digital currency becomes a legal currency, it can be legally circulated nationwide. At this time, if the government do not cancel a country's original credit currency, then dual currency exists. For countries with closed financial systems, digital currency may stagnate in the stage of currency substitution. To some extent, digital currency provides greater support for these countries to stimulate domestic demand and carry out macro control. For countries with a semi-open financial system, although digital currency will bring problems to the mainstream monetary system in the short term, it can reduce inflation expectations in the long run. For countries that are almost completely open to the financial system, the use of digital currency will greatly improve the accessibility of transactions. For residents, digital currency transactions will be more convenient and safe, protect private property, and help individuals withstand the risks of inflation and currency manipulation.

2.The government should take effective measures to tackle with the acceleration of digital currency. In the long run, the speed of digital currency is faster than that in traditional currency, which exacerbates the monetary disturbance. For example, due to the highly developed monetary systems and financial derivatives, the sub-prime mortgage crisis in the United States in 2008 results in a wide spreading. Therefore, some measures should be taken to control the speed of circulation of digital currency. For example, under the personal settlement system, the government can set a larger settlement threshold and transaction amount per day.

3.The government should control the impact on the money multiplier. In the era of digital currency, the currency multiplier will be amplified, and the derivative deposits of the issued currency will be increased dramatically. In economic , an increase of the leverage ratio in financial system will gather financial risks in market. Therefore, appropriate technologies and policies should be adopted to control this amplification effect of the digital currency on money multiplier. In terms of technology, a double-chain structure can be adopted. As a core participant in the consensus, the consortium blockchains collects and validates transactions, determines the status of the system, and stores complete transaction information. The participation of the consortium blockchains safeguards user's privacy through private transmission. In addition, it can also decrypt the transaction content by voting, thus achieving controllable anonymity. In terms of policy, it is recommended to control the trading system rather than the digital currency itself to regulate illegal trading.

4.The government should establish a reasonable digital currency regulatory mechanism by legislation. Because digital currency involves huge economic benefits, risks and problems occur if there are no legal constraints. Therefore, in terms of policy, under the premise of regulating the use of digital currency, it is necessary to adopt a controllable anonymity mechanism that strictly safeguards user's privacy without violating domestic criminal law, international criminal law and international treaties. When it comes to crime, the transaction process can be traced, which avoids the risk of tax avoidance and illegal commodity transactions brought by digital currency.

\section{References :}

[1] FRIEDMAN B. M. The Future of Monetary Policy: The Central Bank as an Army with Only a Signal Corps [J]. International Finance, 2016, 2(3): 321-338.

[2] HUMPHREY D. B., KIM, VALE. Realizing the Gains from Electronic Payments:Cost, Pricing, and Payment Choice [J]. Journal of Money, Credit, and Banking, 2016,33(2): 216-234

[3] BARRDEAR J., KUMHOF M. The Macroeconomics of Central Bank IssuedDigital Currencies [R]. Social Science Electronic Publishing, 2016.

[4] Gao Tiemei. Econometric Analysis Methods and Modeling Eviews Applications and Examples 
(Second Edition) [M]. Tsinghua University Publishing: Beijing, 2017: 221-245.21.23

[5] Zhao Yongjun. The development of Internet finance and its impact on monetary policy. [D]. Dalian: Dongbei University of Finance and Economics, 2015

[6] Zhou Guangyou. The Impact of Electronic Money Development on the Velocity of Money Circulation_An Empirical Study Based on Co-integration. [J]. Economics (Quarterly), 2006, 03: 1219-1234.

[7] Zhou Guangyou. An Empirical Study of the Impact of Electronic Money Development on Money Multipliers [J]. Journal of Quantitative and Technical Economics, 2007, 05: 98-107.

[8] Qin Dazhao. Research on Kalman Filter and Neural Network Combined Model[J]. Computer Knowledge and Technology, 2010,14(06): 3722-3723

[9] Zhai Guanghua, Wang Shunjiu, Pei Ren. Weight estimation and application of artificial neural network based on Kalman filter technique[J]. Journal of Sichuan University (Engineering Science Edition), 2008, 04: 25-28. 